\title{
AN END-TO-END TEST OF A SIMULATED NUCLEAR ELECTRIC PROPULSION SYSTEM
}

\author{
Meliss. V Van Dyke ${ }^{1 \#}$, Ivana Hrbud ${ }^{2 \#}$, Keith Goddfellow $^{3 \#}$ \\ ${ }^{I}$ NASA Marshall Space Flight Center, Propulsion Research Center, Huntsville, AL 35812 \\ ${ }^{2}$ ERC, Inc., NASA MSFC Group, Huntsville, AL 35812 \\ ${ }^{3}$ NASA Jet Propulsion Laboratory, Pasadena, CA 91109 \\ (256) 544-5720, Melissa.Vandyke(a)msfc.nasa.gov
}

\section{ABSTRACT}

The Safe Affordable Fiss:on Engine (SAFE) test series addresses Phase 1 Space Fission Systems issues in particular non-nuclear testing and system integration issues leading to the tesing and non-nuclear demonstration of a $400-\mathrm{kW}$ fully integrated flight unit. The first part of the SAFE 30 test series demonstrated operation of the simulated nuclear core and heat pipe system. Experimental data acquired in a number of different test scenarios $w$ ill validate existing computational models, demonstrated system flexibility (fast start-ups, multiple start-ups/shut downs), simulate predictable failure modes and operating environments. The objective of the second part is to demonstrate an integrated propulsion system consisting of a core, conversion system and a thrister where the system converts thermal heat into jet power. This end-to-end system demonstration sets a precedent for ground testing of nuclear electric propulsion systems. The paper describes the SAFE 30 end-to- $\epsilon$-nd system demonstration and its subsystems.

\section{INTRODUC TION}

Rapid access to any point in the solar system and beyond requires advanced propulsion concepts that can provide extremely high specific impulse, high specific power, and high thrust-to-power ratios. NASA's vision for the $21^{\text {st }}$ century and beyond is challenging scientific and engineering communities to develop propulsion technologies which will enable ambitious exploration of the solar system and its in erstellar neighborhood, commercialization of space and eventual human colonization beyond Earth (Schmidt, 1998). Two technologies that synergistically offer tremendous potential for the immediate future are advanced electric propulsion and nuclear energy Space nuclear systems

\footnotetext{
* AIAA Member

Copyright $(2002$ by the American Inst tute of Aeronautics and Astronautics
}

have recently received a renewed interest due to their versatility, high-power density, and ability to support power-intensive missions (Borowski et al., 1998). The dualism of providing both propulsion and power, linked with the enormous energy available per unit mass of fission fuel, has significant benefits to future programs involving nuclear thermal rockets (Watson, 1994), efficient conversion systems, space-based nuclear reactors, and nuclear electric propulsion (Allen, 1995).

To date, only a few electric propulsion concepts can support the high power requirements for future missions. Due to their specific impulse operating range, advanced ion and Hall thrusters (Sankovic, 1999) are the most likely candidates to be used in the near term for a wide variety of missions spanning from Low Earth Orbit to interstellar space. Depending on the mission scenario/profile, this efficient electric propulsion device can be powered by solar or space nuclear power. Beyond the use of these very efficient systems, mid to far term solution might include propulsion concepts such as the MagnetoPlasmaDynamic (MPD) thruster (Polk, 1999, LaPointe, 2000), the Variable Specific Impulse Magnetoplasma Rocket (VaSIMR) (Chang-Diaz, 1995), the Pulsed Inductive thruster (PIT) (Dailey, 1993).

Research in the field of electrostatic acceleration has been conducted since the late 1950s' resulting in a number of different devices and ionization methods capable of supporting space propulsion. These devices use suitable grid electrodes for ion extraction/acceleration converting electric energy to kinetic energy. The most commonly used ion source is based on electron bombardment where plasma is generated by electrons colliding with neutral gas. Thrusters based on the Kaufman concept use weak magnetic fields for ion/electron separation. To date, the most successful ion thruster developed by NASA is the NSTAR engine, which currently flies on board the Deep Space 1 (DS 1) spacecraft. 


\section{SAFE 30 TEST SERIES}

Power of 10-100 kW and specific power of $10-30 \mathrm{~kg} / \mathrm{kW}$ characterize Phase 1 Space Fission Systems (SFS) possibly used for nuclear electric propulsion (NEP) and spacecraft/surface powerplants. These systems are targeted for, but are not limited to, space science missions extending from planetary orbiters and landers to interstellar precursor probes. The Safe Affordable Fission Engine (SAFE) test series addresses some system issues of Phase 1 SFS in particular non-nuclear testing and system integration issues leading to the testing and non-nuclear demonstration of a $400-\mathrm{kW}$ fully integrated flight unit. The SAFE test program (van Dyke, 2001) has a phased structure/approach, which started with module testing (MUTT) (van Dyke 2000) and will be completed with a full propulsion system demonstrator including core, thruster, reflectors, radiators, etc.

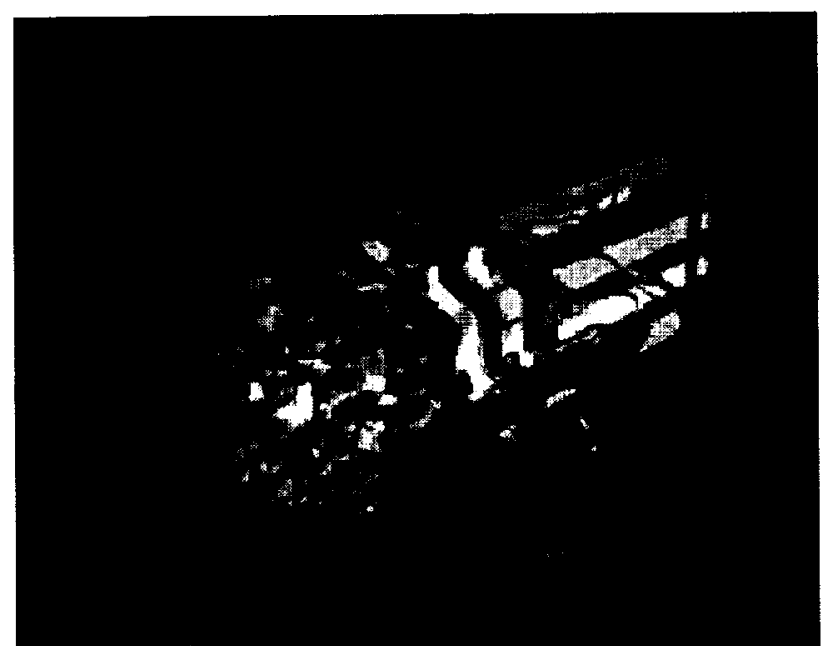

Figure 1 - Infrared Picture of Simulated ResistanceHeated Core and Heat Pipes at about $650^{\circ} \mathrm{C}$.

The SAFE 30 is a full core test designed for a power input of $30 \mathrm{~kW}$ using resistance heating to simulate the thermal heat from a fission reactor. The core has a hexagonal footprint of 48 stainless steel tubes and 12 stainless steel sodium filled heat pipes. It is assembled in a modular fashion where a module consists of 4 stainless steel tubes and one heat pipe welded together longitudinally. The heat pipes are $119 \mathrm{~cm}$ and the tubes are $43 \mathrm{~cm}$ long, while the diameter of both is $2.54 \mathrm{~cm}$. Resistance heaters, which are inserted into the stainless steel tubes, are made from graphite rods and are rated for up to $1.3 \mathrm{~kW}\left(0.34 \Omega\right.$ at $\left.1000^{\circ} \mathrm{C}\right)$. The heaters generate thermal heat closely simulating the thermal profile of an actual nuclear (fission) system. The nominal power input to a heater is about $750 \mathrm{~W}$ generating a temperature of $1000{ }^{\circ} \mathrm{C}$. The heat pipes embedded in the core remove the heat out of the cure where the maximum isothermal operating temperature for the heat pipes is about $750^{\circ} \mathrm{C}$. Figure 1 illustrates an infrared picture of the SAFE 30 core where the glowing heat pipes are in the background and the foreground shows the heater electrical interface. Figure 2 depicts a typical temperature profile of the heat pipes in the core and outside the core (us=upstream/ds=downstream of copper heat exchanger, see below) as a function of time during a test series at JPL in May 2001.

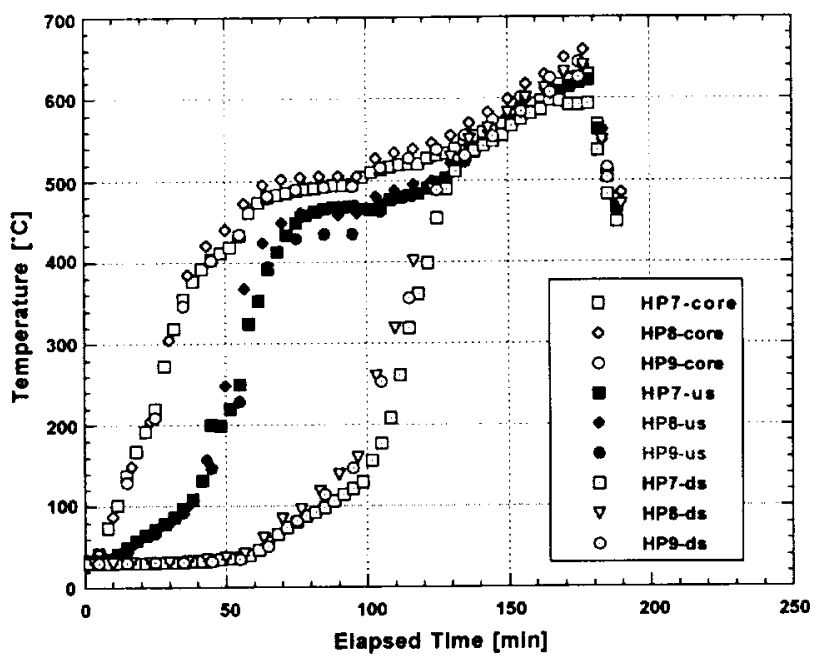

Figure 2 - Typical Temperature Behavior as Function of Time

The goal of the first part of the SAFE 30 test series was to obtain experimental data demonstrating operation of the simulated nuclear core and heat pipe system. Experimental data acquired in a number of different test scenarios will validate existing computational models, demonstrate system flexibility (fast start-ups, multiple start-ups/shut downs), and simulate predictable failure modes and operating environments. The objective of the second part is to demonstrate an integrated propulsion system consisting of a core, conversion system and a thruster where the system converts thermal heat into jet power.

\section{ION THRUSTER - BACKGROUND}

Ion thrusters are characterized by continuous, low to moderate power level operation while electrostatically accelerating positively charged particles (atomic/ molecular ions, colloidal particles, etc.). The characterization of electrostatic systems is based on the production mechanisms of charged particles; these can be summarized as electron bombardment, RF ionization, contact/surface and field emission ionization. The main components of a Kaufman type ion thruster are discharge chamber containing magnet system and electron emitter (hollow cathode), optics/acceleration grids, neutralizer 
hollow cathode, and power supplies for each subsystem. Figure 3 illustrates a schematic of such a thruster whose ion source is based on electron bombardment. The hollow cathode produces and emits electrons into the discharge cavity of the thruster. These primary electrons drift towards the anode transversing a weak axial magnetic field, which causes a spiral motion. The electrons collide and ionize neutral atoms injected into the discharge chamber. The magnetic field prevents premature losses of primary electrons to the anode and ion losses to thruster walls. The electron kinetic energy and the diameter of the discharge chamber determine the strength of the magnetic field, which can be provided by either a permanent or electro magnet. The high electrostatic potential established between the plasma and the acceleration grid extracts and accelerates ions. A cathode at the exit plane of the thruster emits electrons to neutralize the ion beam. It is crucial for the operation of this thruster to keep the net charge of the beam zero. The thrust and specific impulse depend on net acceleration potential, mass-to-charge ratic of the ion and the ion density.

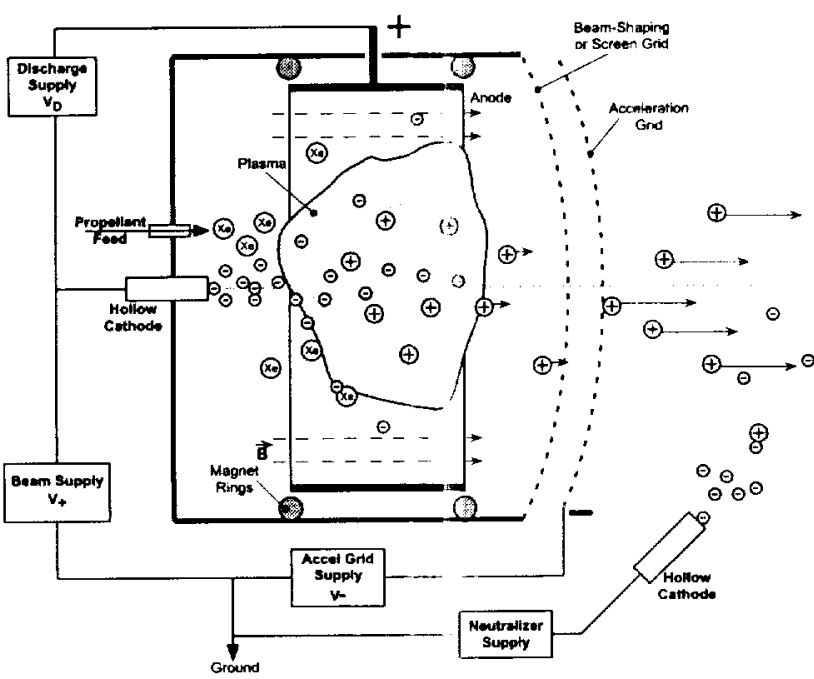

Figure 3 - Schematic of Ion Thruster.

Ion thrusters have been diveloped and tested since the 1950's accumulating an extensive laboratory and flight history. The first ion thruster ever flown was SERT I (Space Electric Rocket Test, 1964), which used vaporized Mercury as propellant (Cybulski, 1965). The latest in a long list of successfully used ion thrusters in space is the $30-\mathrm{cm}$ NSTAR ion thruster propelling the Deep Space 1 (DS 1) space raft, which flew by an asteroid and the comet 'Borrelly'. The thruster was designed for $2.3 \mathrm{~kW}$ and a bcam voltage of $1,000 \mathrm{~V}$ using Xenon as propellant. In-flight performance characteristics include specific impulse of 3,200 s and thrust of $120 \mathrm{mN}$ resulting in an overall efficiency of 62 $\%$. As of September 24, 2001. marking the day of the fly-by at the comet, the thruster logged more than 14,200 hours of (continuous) operation with a propellant through-put of $65 \mathrm{~kg}$. While the performance of the flight unit is carefully monitored, a spare NSTAR ion thruster is pushed to the limit in ground testing at the JPL test facilities. The spare unit accumulated has 18,800 hours of operation and expended $155 \mathrm{~kg}$ of Xenon (Brophy, 2001).

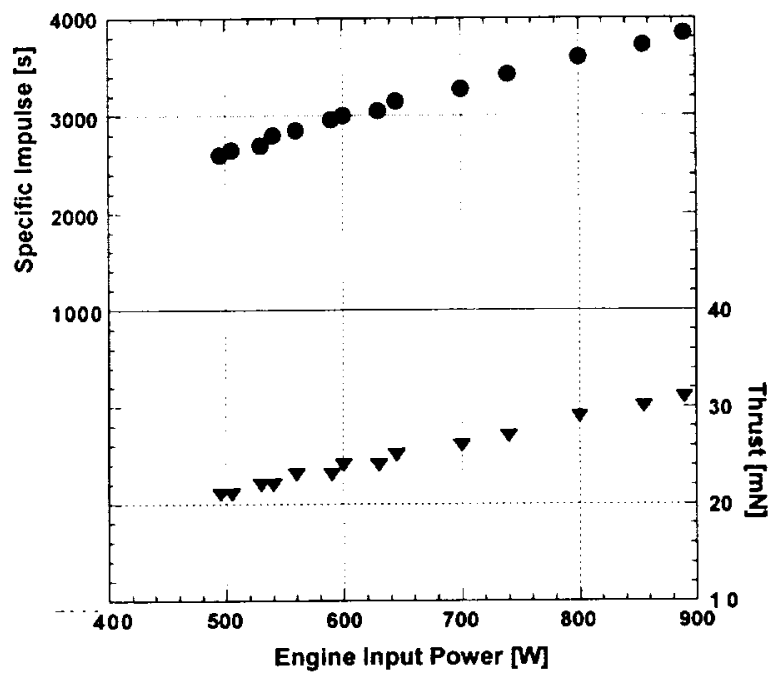

Figure 4 - Specific Impulse and Thrust as a Function of Input Power (data extracted with permission from Brophy 1993).

The demand of future planetary missions, the need to reduce launch cost and to significantly extend mission lifetime motivated the push for the development of a scaled down version of the successful $30-\mathrm{cm}$ NSTAR ion engine. A program was established to 1.) develop a 15$\mathrm{cm}$ Xenon ion thruster, 2.) explore a cluster configuration of four $15-\mathrm{cm}$ ion thrusters and 3.) provide a testbed for advanced acceleration optics and materials (Brophy, 1993). To date, advanced grid technologies include optics fabricated from diamond film, dished graphite grids, molybdenum and carbon-carbon (Mueller, 1993) acceleration systems.

The $15-\mathrm{cm}$ ion engine is designed for a maximum input power (to the power processing unit) of $1.25 \mathrm{~kW}$, while it can be safely operated at a beam power as low as $200 \mathrm{~W}$. Figure 4 illustrates a typical trend for specific impulse and thrust as a function of power input operating with molybdenum grids at a constant beam current of $500 \mathrm{~mA}$. Performance characteristics with carbon-based grid materials are comparable, although in general performance values are slightly lower. However, carbon-based grids supersede with extremely low erosion rate and superior sputter resistance. These properties are key to significantly extend the lifetime of ion thrusters. Preliminary performance evaluation for molybdenum and graphite grids indicates a total thruster efficiency of 
about 52 to $66 \%$ with an uncertainty of up to $10 \%$ (Brophy, 1993). Figure 5 shuws the $15-\mathrm{cm}$, slotted Carbon-Carbon grid ion thruster as it is mounted to the door of the vacuum chamber at the JPL facilities. The set-in picture is an enlarged section of the grid revealing the slot structure.

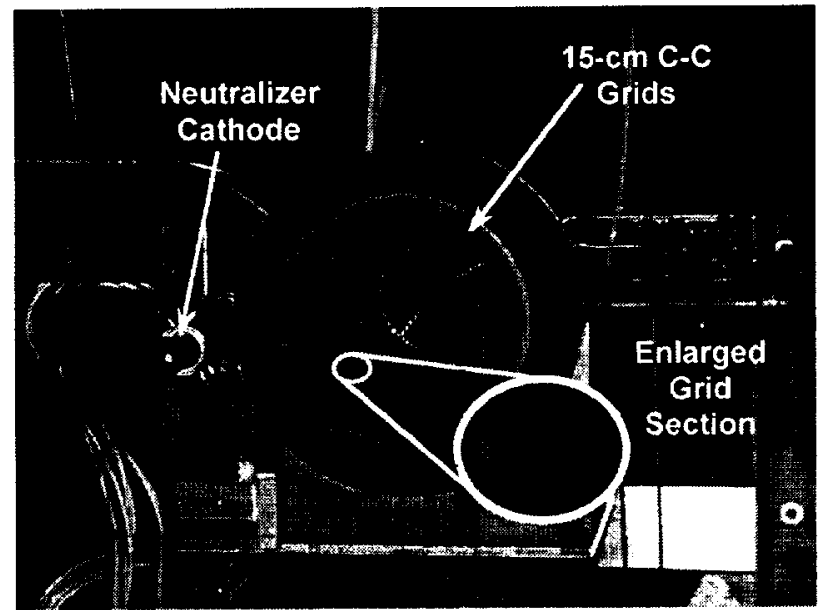

Figure 5 - 15-cm, Slotted Carbon-Carbon Grid Ion Thruster

\section{END-TO-END SYSTEM I)EMONSTRATION}

The end-to-end system demonstration consists of the SAFE 30 simulated core, $350-W$ Stirling engine, DC/DC converter and $15-\mathrm{cm}$ ion thruster with slotted carboncarbon grids. The purpose of the end-to-end tests is to showcase the nuclear electric propulsion (NEP) concept using thermal heat released by fission processes and converting that heat to kinetic energy- by a simulated approach with inexpensive off-the-shelf materials in a relevant environment.

For the end-to-end system demonstration, the SAFE 30 core is assembled in its modular manner and consists of two heating zones each powered by a separate power supply. Zone One encompasses three modules containing heat pipes. There are three strings of heaters wired in parallel where each string contains four heaters in series. These twelve heaters are powered by a HP power supply providing $100 \mathrm{~A}$ at $100 \mathrm{VDC}$. The remaining nine modules comprise Zone Two which is provided with heating power by a 400-A, 200-VDC Linde power supply. A modile in this zone has four stainless steel tubes welded to a blanked-off pipe of the same dimensions as the heat pipe. The heaters are wired in 18 parallel strings where wach string contains two heaters in series.

As it is illustrated in Figui 6 , the protruding three heat pipes are clamped to a copper block, which in turn is attached to the heater head of the $350-W$ Stirling engine. The Stirling engine $i$; an off-the-shelf device manufactured by Stirling Technology Company (STC). The Stirling engine converts thermal energy into electric energy based on the thermodynamic process described by the Stirling cycle outlined elsewhere (Schreiber, 2001). This engine is based on the 'free-piston' power conversion concept using thermal-mechanical oscillations to drive a linear alternator. The efficiency of a Stirling cycle can be maintained over a wide range of power and can approach Carnot efficiencies. The active heat exchange zone on the heater head is about $4.5 \mathrm{~cm}$ wide operating at a nominal temperature of $650{ }^{\circ} \mathrm{C}$. The copper block clamps precisely over that region to ensure proper heat input to the heater head of the Stirling engine. The Stirling engine is equipped with a balance motor compensating for vibrations generated by the engine during entire operation sequence (initial start-up, power generation, shut-down). The working fluid of the engine is Helium at a pressure of 45 to 52 bar, while the alternator generates $350 \mathrm{~W}$ at $175 \mathrm{VAC}$.

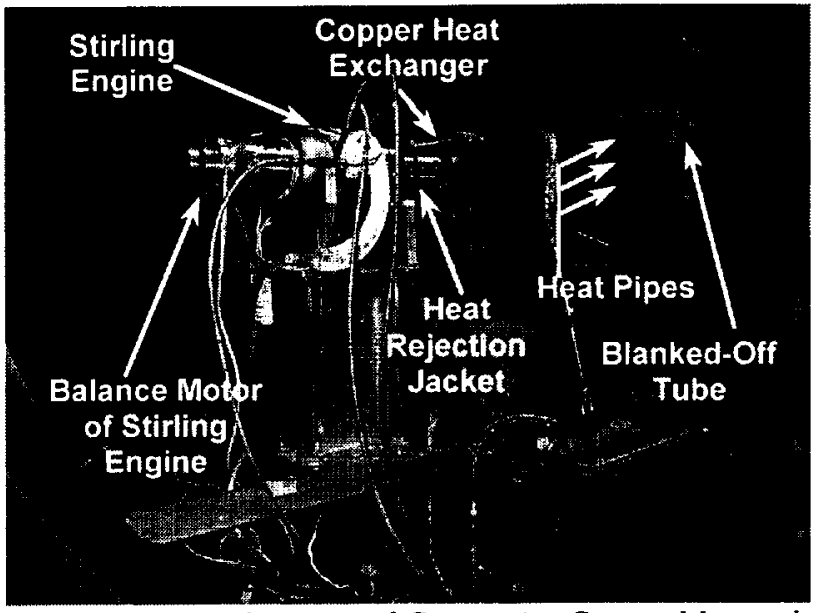

Figure 6 - Heat Source and Conversion System Mounted in the Vacuum Chamber at JPL.

The power support system for the ion thruster consists of four separate power supplies providing power to the subsystems of the thruster as described above. However, the power generated by the Stirling engine replaces the conventional beam supply. All other subsystems of the thruster will be maintained and controlled by the power support system. The powertrain between the Stirling engine and the ion thruster is illustrated in Figure 7. The Stirling engine controller processes the generated power and provides logistics to the Stirling engine depending on operating conditions and power demand (load). The control board algorithm manages the proper loading of the Stirling engine. Sensing circuitry monitors power demand at the output and accordingly the control board ties in or removes stages of a resistive load array. The AC power generated by the Stirling engine is processed by rectifier circuitry and converted to an output of about $123 \mathrm{VDC}$ and $3 \mathrm{~A}$. 
A crucial component of the piwertrain is the $\mathrm{DC} / \mathrm{DC}$ converter, which conditions the power for the beam supply of the ion thruster. The major functions of this device are voltage step-up, current and inrush current limitation, and power enable/inhibit control. The DC/DC converter steps up the input voltage of about $123 \mathrm{VDC}$ to 1000 VDC with appropriate transformer circuitry. In addition, the device limits the inrush current during the start-up sequence of the iin thruster. Without appropriate protection circuitry during this period, the current drawn by the systen could be very high, damaging all crucial components of the powertrain. This circuit (consisting of an IGB $\Gamma$ and capacitor array) monitors the input current to thic converter. In the case that the rate of rise is too high the IGBTs are switched on and off at high frequency allowing the capacitor bank to charge at incremental current drawn during the pulses. The inhibit switch is another important part of the converter, which is controlled by the power support system of the ion thruster. The switch terminates the high voltage provided by the converter to the thruster in case of malfunction or system failure. The power support system provides a signal of $5 \mathrm{VDC}$ to engage the inhibit mode of the switch and a $0-V D C$ signal to disengage the mode. Another feature of the converter is the external programming, which sets the maximum output current by a signal provided by an external power supply. The input signal is between 0 and $5 \mathrm{~V}$, where the output current is $0 \mathrm{~A}$ at $0 \mathrm{~V}$ and $500 \mathrm{~mA}$ at $5 \mathrm{~V}$. Any desired output current within this limit follows a linear relationship depending on the input voltage. The DC/DC converter is rated for a power input of $500 \mathrm{~W}$ and its efficiency is about $90 \%$. Table 1 summarizes electrical characteristics of the powertrain at locations indicated in Figure 7.

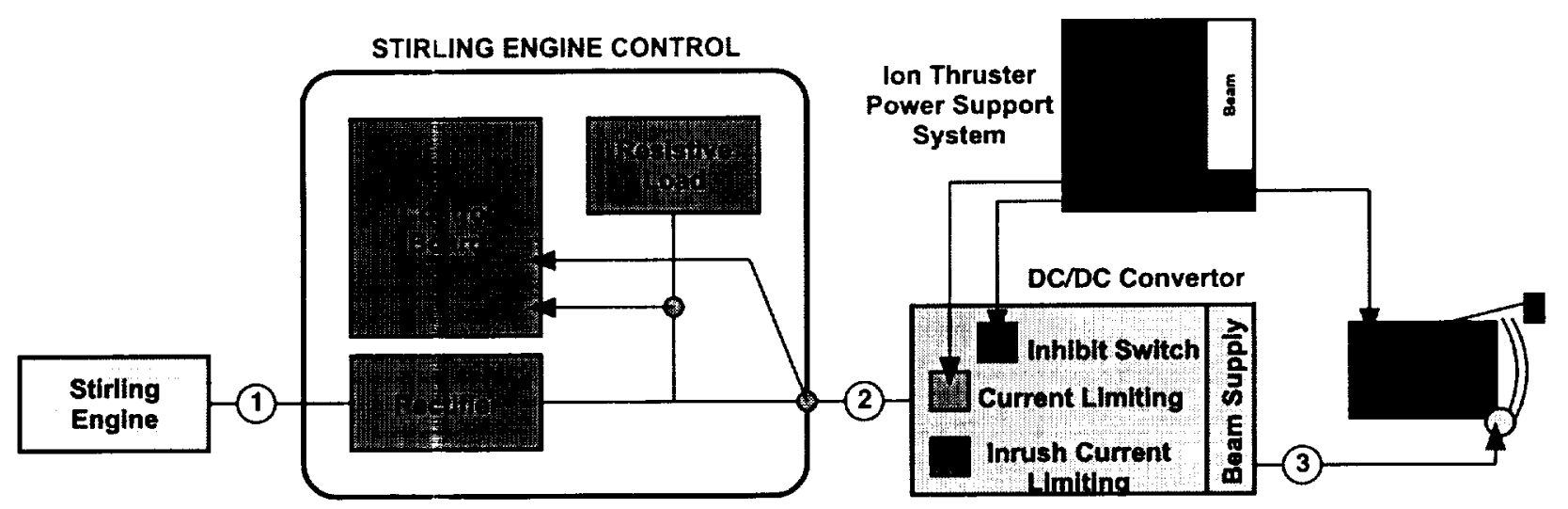

FIGURE 7. Schematic of the Powertrain Providing Beam Power to the Ion Thruster from the Stirling Engine.

TABLE 1. Expected Electrical Characteristics at Selected Locations of the Powertrain.

\begin{tabular}{lccc}
\hline Location & $\mathbf{1}$ & $\mathbf{2}$ & $\mathbf{3}$ \\
\hline Voltage & $170 \mathrm{VAC}$ & $123 \mathrm{VDC}$ & $1000 \mathrm{VDC}$ \\
Current & $2 \mathrm{~A}$ & $2.9 \mathrm{~A}$ & $300 \mathrm{~mA}$ \\
Power & $350 \mathrm{~W}$ & $350 \mathrm{~W}$ & $300 \mathrm{~W}$ \\
\hline
\end{tabular}

\section{CONCLUSIONS}

The end-to-end system demonstration sets a precedent for ground testing of nuclear electric propulsion systems. Simulating the thermal heat released by a nuclear core with resistance heaters is inexpensive and can be performed in a timely manner. More importantly, integration issues, system behavior/failure and componen1 matters are quickly identified and accurately analy zed. The success of this program led by NASA MSFC is shared and depends on the collaboration with NASA centers, other government agencies, in lustry and academia.
The combination of long life, low specific mass, and high specific impulse is unique among electric propulsion systems, making NEP systems well suited for the challenging missions envisioned by NASA.

\section{ACKNOWLEDGMENTS}

This program was funded through the NASA Advanced Space Transportation Program (ASTP), whose support is gratefully acknowledged. The authors wish to thank Dr. James Polk, JPL (Pasadena, CA), for facilitating the end-to-end demonstration at JPL facilities; Dr. John R. Brophy, JPL (Pasadena, 
CA), for providing performance characteristics of the 15-cm, carbon-carbon grid ion thruster; Mr. Jack Augenblick and Mr. lain Williford, Stirling Technology Company (Kennewick, WA), for providing technical assistance on the Stirling engine.

\section{REFERENCES}

Allen, D. M., Bennett, G. I., El-Genk, M. S., Newhouse, A. R., and Rose, M. F., "Maintenance of the U.S. Space Nuclear Power Program: An AIAA Position Paper," $46^{\text {th }}$ International Astronautical Congress, IAF-95R.1.05, Oslo, Norway, Octoher 1995.

Borowski, S. K., Dudzinski, L. A., and McGuire, M. L., "Vehicle and Mission Design Options for the Human Exploration of Mars/Phobos Using Bimodal NTR and LANTR Propulsion," NASA/TM-1998-208834, December 1998.

Brophy, J.R., Personal Communication, November 2001.

Brophy, J. R., Pless, L. C., Mueller, J., Anderson, J. R., "Operating Characteristics of a $15-\mathrm{cm}$ Diameter Ion Engine for Small Planetary Spacecraft," International Electric Propulsion Conference, IEPC-93-110, September 1993, Seattle, WA.

Chang-Diaz, F. R., Braden, E., Johnson, I., Hsu, M. M., and Yang, T. F., "Rapid Mars Transits with Exhaust-Modulated Plasma Propulsion," NASA Technical Paper 3539, March 1995.

Cybulski, J. R., et. al., "Results from SERT I Ion Rocket Flight Test," NAS^ Technical Note D$2718,1965$.

Dailey, C. L. and Lovberg, R H., "The PIT MkV Pulsed Inductive Thruster," NASA CR 191155 , July 1993.

LaPointe, M. R. and Sankovic J. M., "High Power Electromagnetic Propulsion at the NASA Glenn Research Center," Proce idings of the Space Technologies and International Forum (STAIF) 2000 Conference, American Institute of Physics Conference Proceedings 504, M. El-Genk (ed), January 2000, pp. 1538-43.

Mueller, J., Brown, D. K., Garner, C. E., Brophy, J. R., "Fabrication of Carbun-Carbon Grids for Ion Optics," International Electric Propulsion Conference, IEPC-93-112, September 1993, Seattle, WA.

Polk, J., Tikhonov, V., and Semenikhin, S., "200-kW Lithium-Fed Thruster Development and Preliminary Test," $35^{\text {th }}$ Joint Propulsion Conference, AIAA 99-22×5, Los Angeles, CA, June 1999.
Sankovic, J., Oleson, S. and LaPointe, M., "NASA GRC Activities in High Power Electric Propulsion," Proceedings of the NASA/JPL I $0^{\text {th }}$ Advanced Space Propulsion Workshop, April 1999, pp. 665-681.

Schmidt, G. R., "Propulsion Research and Technology at NASA Marshall Space Flight Center," $34^{\text {th }}$ AIAA Joint Propulsion Conference, AIAA 98-3230, Cleveland, OH, July 1998.

Schreiber, J., "Tutorial on Free-Piston Stirling Power conversion Technology - How does it Work?," presented at the Space Technology and Applications International Forum (STAIF) 2001 Conference, Albuquerque, NM, February 2001.

van Dyke, M. K., Houts, M., Pederson, K., Godfroy, T., Dickens, R., Poston, D., Reid, R., Salvail, P., Ring, P. "Phase 1 Space Fission Propulsion System Testing and Development Progress," Proceedings of the Space Technologies and International Forum (STAIF) 2001 Conference, American Institute of Physics Conference Proceedings 552, M. El-Genk (ed), February 2001, pp. 837-42.

van Dyke, M. K., Godfroy, T., Houts, M., Dickens, R., Dobson, C., Pederson, K., Reid, R., Sena, T. "Results of a First Generation Least Expensive Approach to Fission Module Tests: NonNuclear Testing of a Fission System," Proceedings of the Space Technologies and International Forum (STAIF) 2000 Conference, American Institute of Physics Conference Proceedings 504, M. El-Genk (ed), January 2000, pp. 1211-17.

Watson, C.W., "Nuclear Rockets: High-Performance Propulsion for Mars, " LA-12784-MS, Los Alamos National Laboratory, May 1994. 


\title{
AN END-TO-END TEST OF A SIMULATED NUCLEAR ELECTRIC PROPULSION SYSTEM
}

\author{
MELISSA VAN DYKE
}

IVANA HRBUD, NASA MSFC, TD4O, HUNTSVILLE, AL

KEITH GOODFELLOW, NASA JPL, PASADENA, CA 


\section{PRESENTATION OUTLINE}

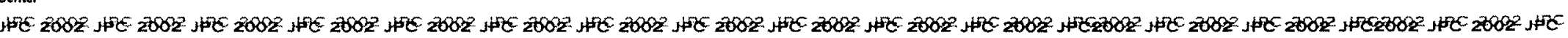

* SAFE DEVELOPMENT PATH

* OBJECTIVES

* SAFE30 POWERTRAIN

* POWERTRAIN COMPONENTS

* EXPERIMENT AT JPL

* RESULTS

* SUMMARY 


\section{SAFE DEVELOPMENT PATH}

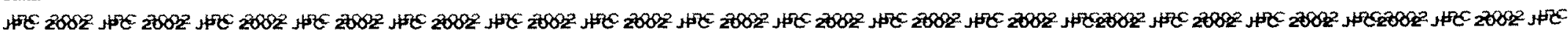

a
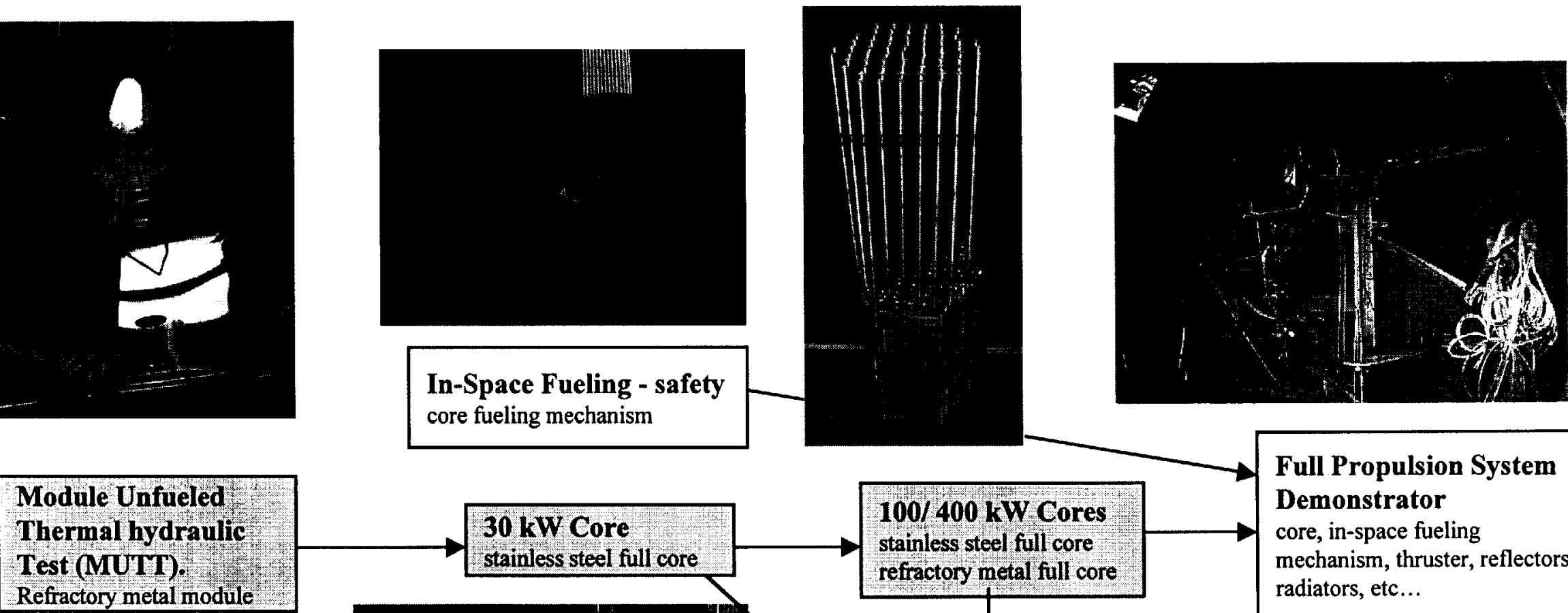

In-Space Fueling - safety core fueling mechanism
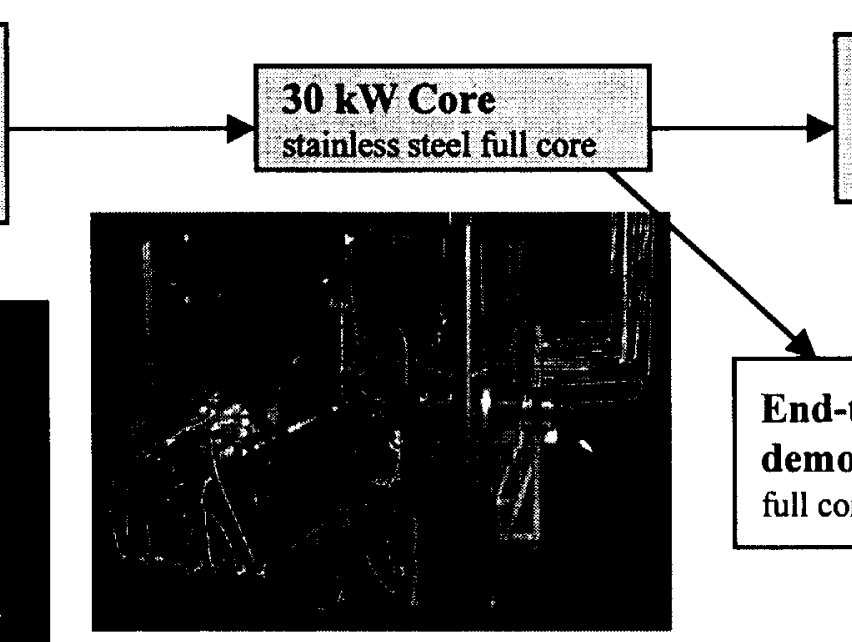

\section{$100 / 400 \mathrm{~kW}$ Cores stainless steel full core refractory metal full core}

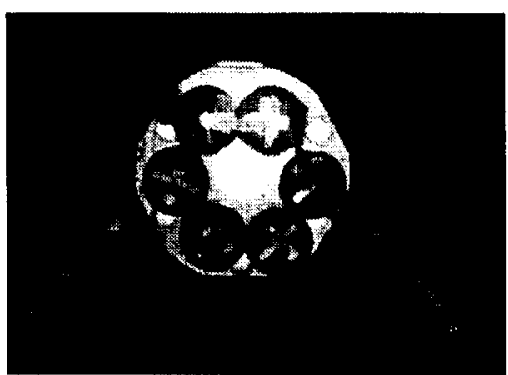

Balance of Plant

thrusters, reflectors, radiators, shielding, energy conversion, bus design, etc...

End-to-end system demonstrator full core integrated with thruster

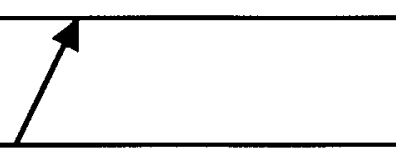

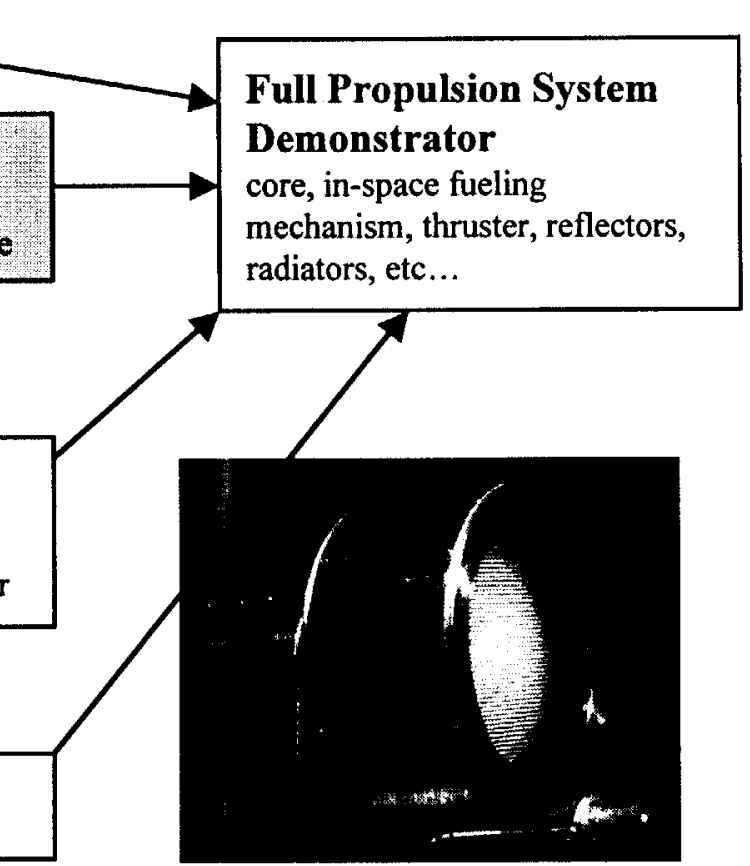




\section{OBJECTIVES}

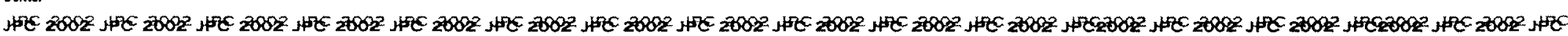

* Demonstrate operation of a resistance-heated simulated nuclear core and heat pipe system.

Validating existing computational models,

: Demonstrate system flexibility (fast start-ups, multiple starts/shutdowns),

Simulate predictable failure modes,

Operating environments.

* Demonstrate integrated propulsion system consisting of core, conversion system and thruster.

* Identify and address integration issues:

* Stirling operation/loading must be ensured at all times:

: Response time of Stirling load share must be faster than thruster recycle event,

* Heat coupling and exchange,

* Vibration, balancing and damping in dynamic systems,

* Electric interfaces:

Electrical connections to heaters,

: Electric isolation between components (DC/DC converter, thruster power system)

EMI isolation and dynamics of cabling. 


\section{SAFE-30 POWER TRAIN}

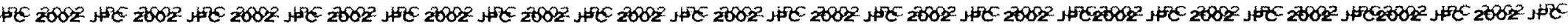

\section{Thermal Energy}

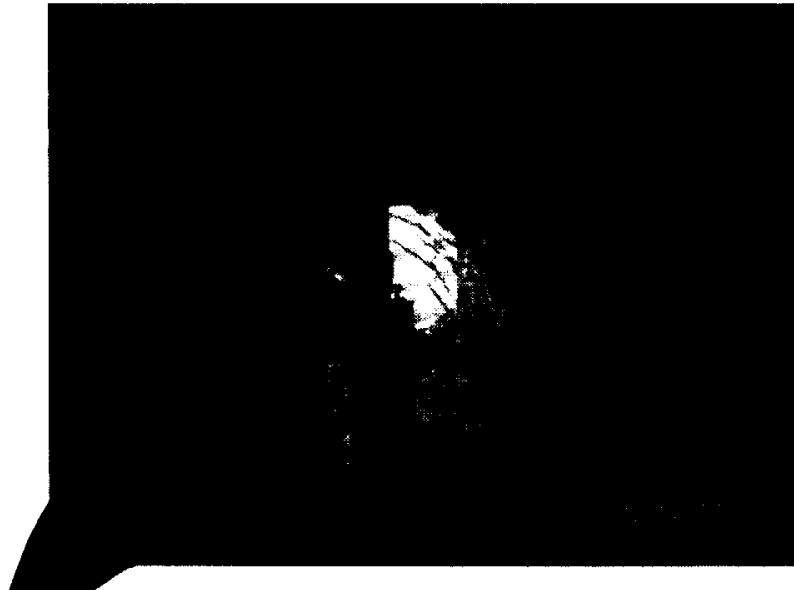

\section{Power Conversion}

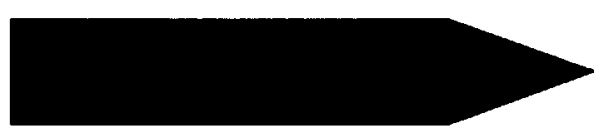

\section{Kinetic Energy}

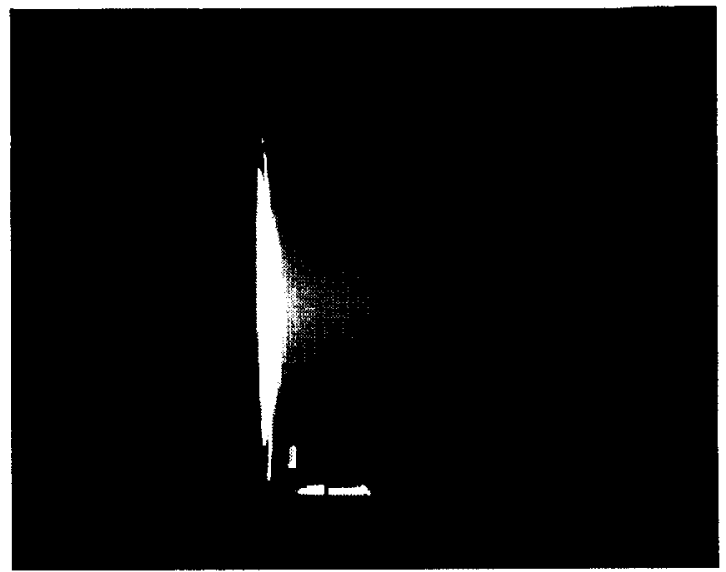

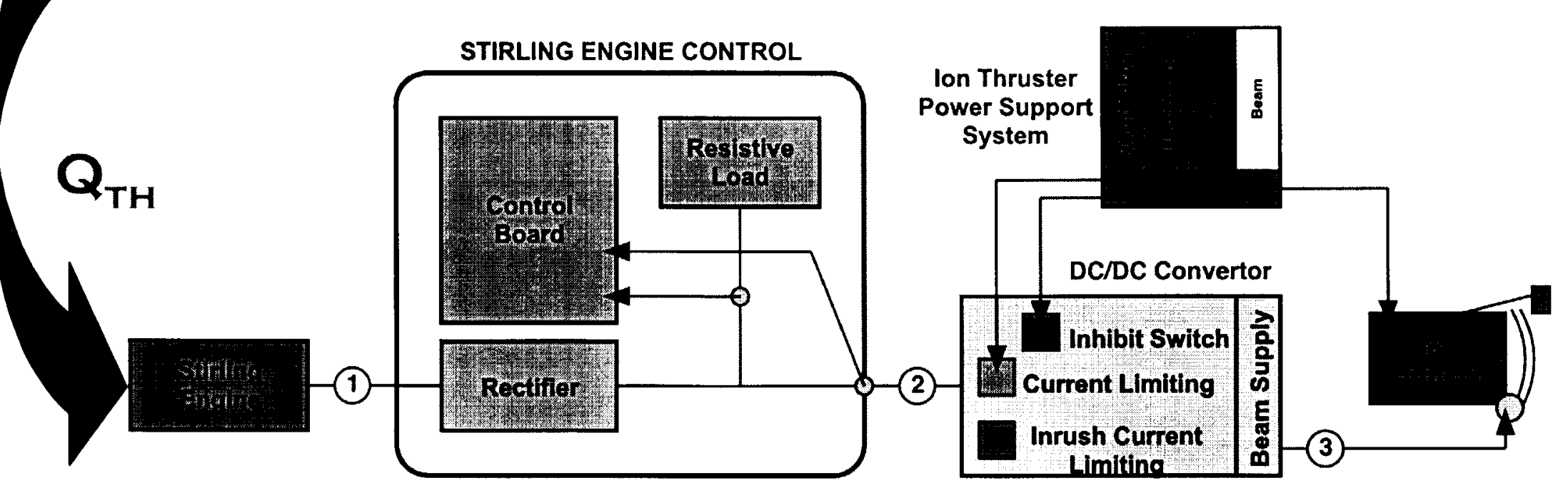




\section{THERMAL ENERGY}

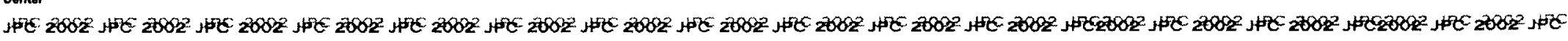

* SAFE 30 Core:

* Core has hexagonal footprint comprised of 12 modules.

: Zone One ( 3 modules): four SS tubes welded longitudinally to sodiumfilled heat pipe.

: Zone Two (9 modules): same as above where heat pipe substituted with blanked-off SS tube.

* Stainless steel tubes hold resistance heaters:

Graphite rods rated at $1.3 \mathrm{~kW}\left(0.34 \Omega / 1000^{\circ} \mathrm{C}\right)$

Operation: $750 \mathrm{~W}\left(1000^{\circ} \mathrm{C}\right)$

* Electric Power Input to Core:

* Zone One:

: HP PS: 100 A/100 VDC

String: four heaters in series

3 strings in parallel

- Zone Two:

: Linde PS: 400 A/200 VDC

String: two heaters in series

18 strings in parallel

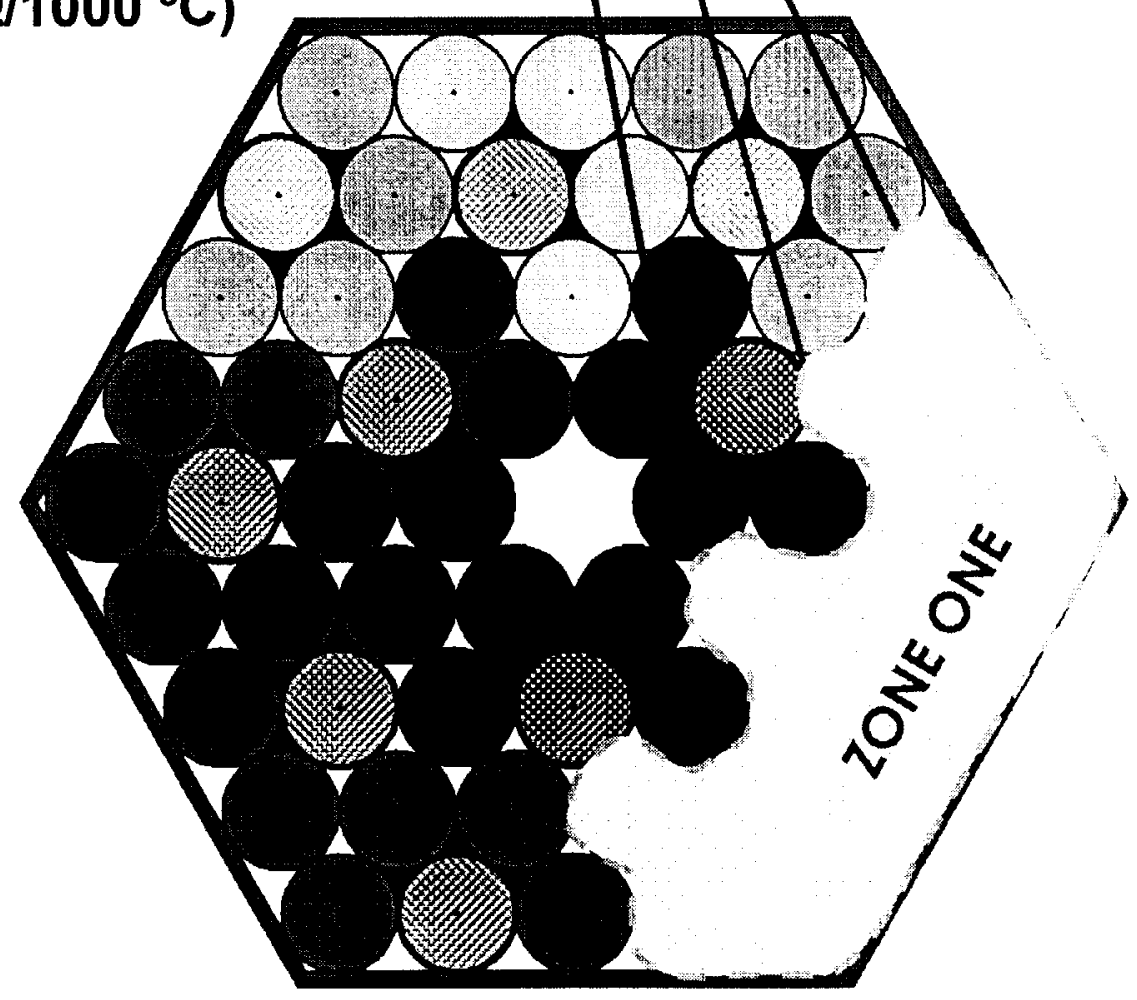




\section{TEMPERATURE PROFILE}

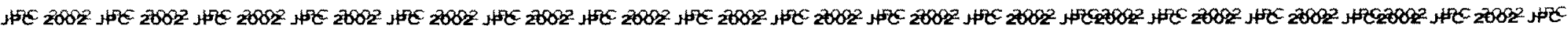
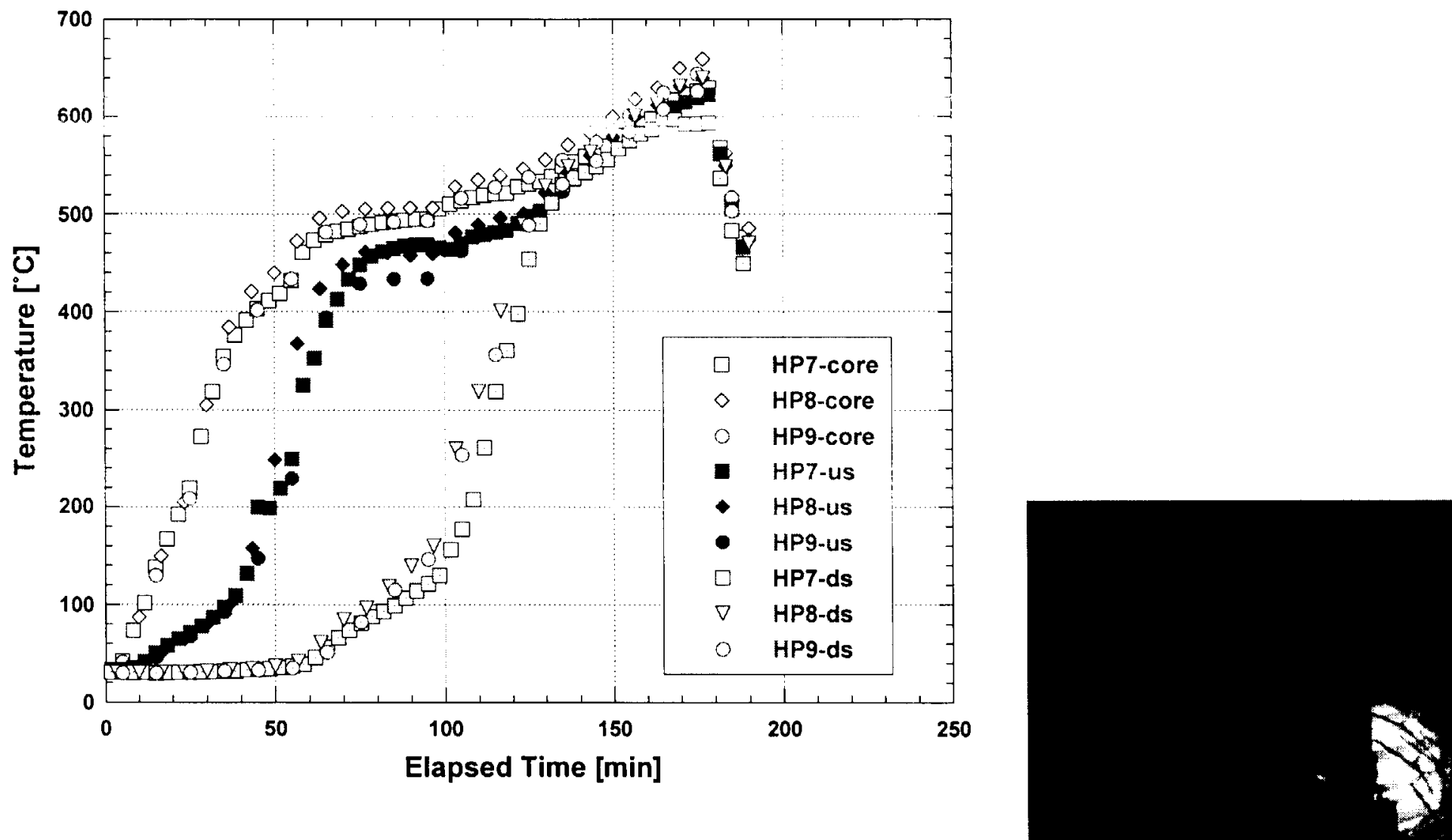


\section{CONVERSION SYSTEM}

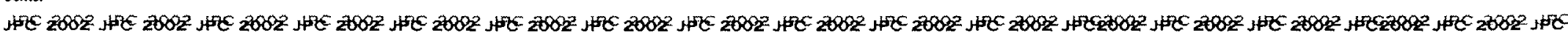

\section{* Stirling Engine by Stirling Technology Company}

* 'Free-piston' concept using thermal-mechanical oscillations to drive linear alternator.

* Control Box: power processing and loading of engine

* Balance Motor for Vibration Compensation

* Operating Temperature: $650^{\circ} \mathrm{C}$

* Working Fluid:

* Electric Output:

Stirling Engine: 350 W/175 VAC

Control Box: 350 W/123 VDC

Helium at 45-52 bar

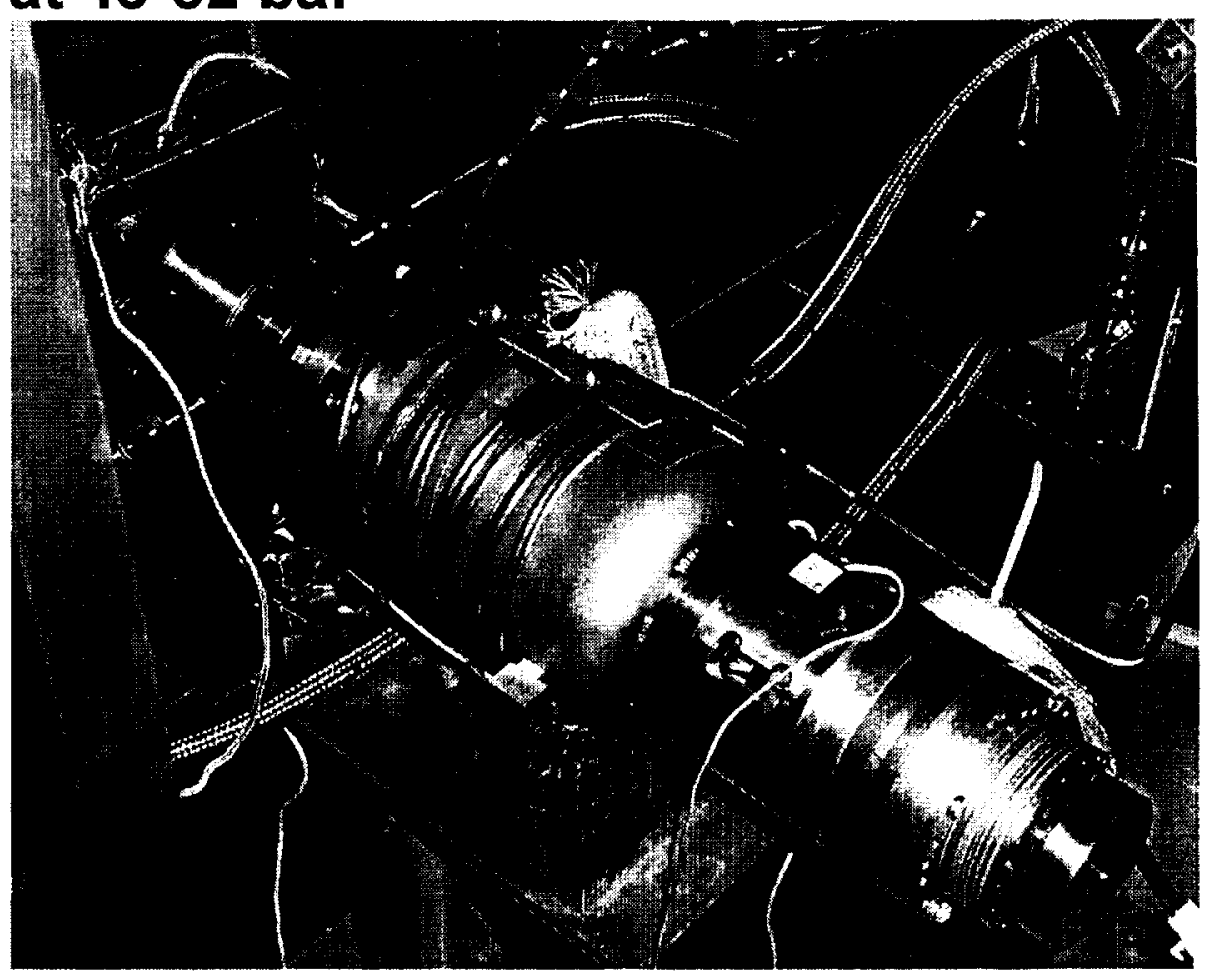




\section{CONVERSION SYSTEM}

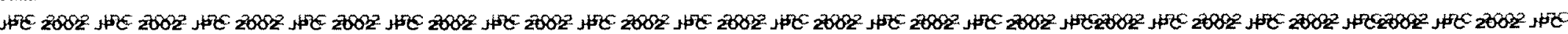

\section{* DC/DC Converter}

* Commercially available unit by Schaefer, MA.

* Voltage Step-Up:

123 VDC $\Rightarrow 1000$ VDC

$500 \mathrm{~W}, 90 \%$

* Inrush-Current Limiting

Inhibit Switch

* Current Limiting

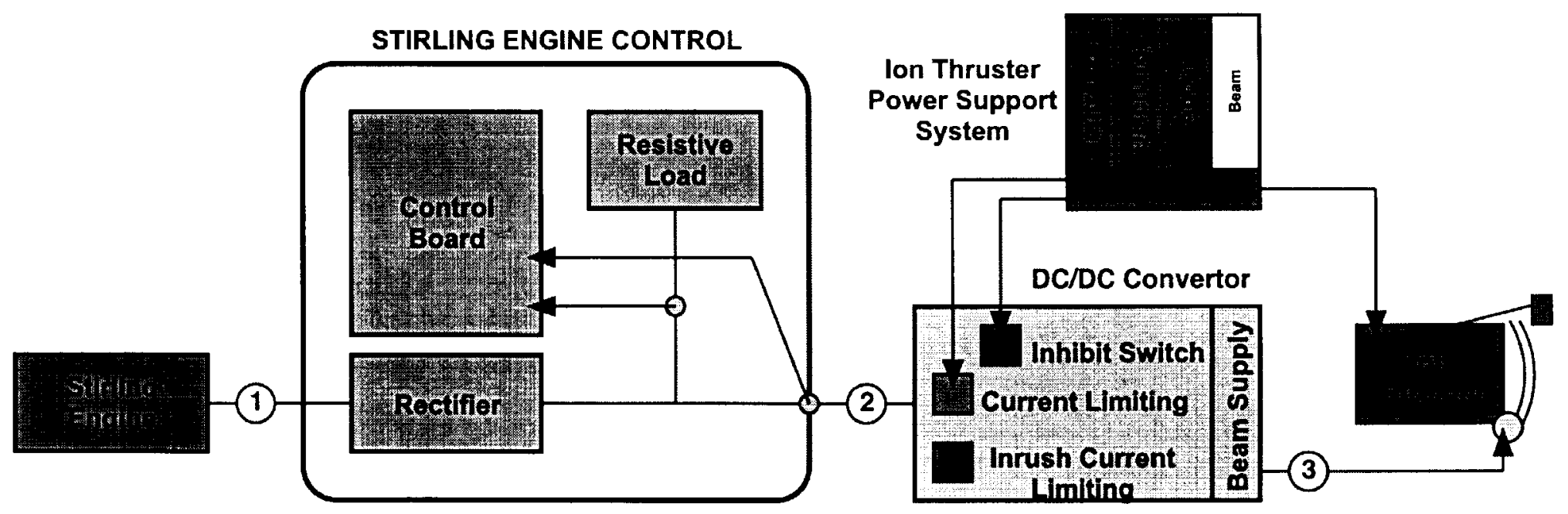




\section{ION THRUSTER}

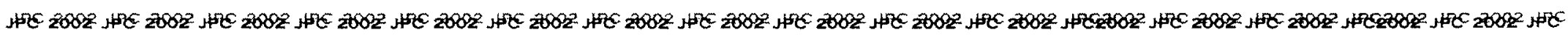

$* 15-\mathrm{cm}$ lon Engine

* Slotted, Carbon-Carbon Grids

* Power Input: 1.25 kW

Efficiency: $60 \%( \pm 5 \%)$

Specific Impulse and Thrust as a Function of Input Power Beam Current $=500 \mathrm{~mA}$

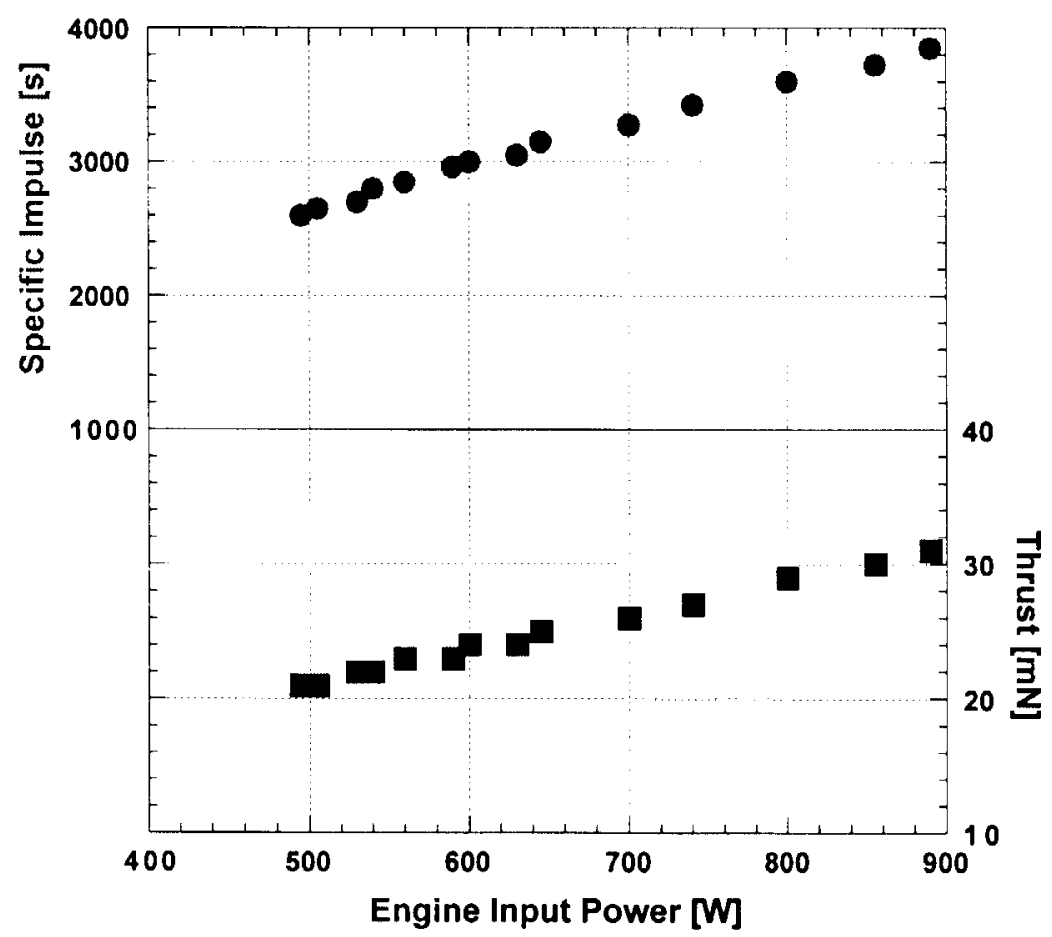

IVANA HRBUD/MSFC-TD40
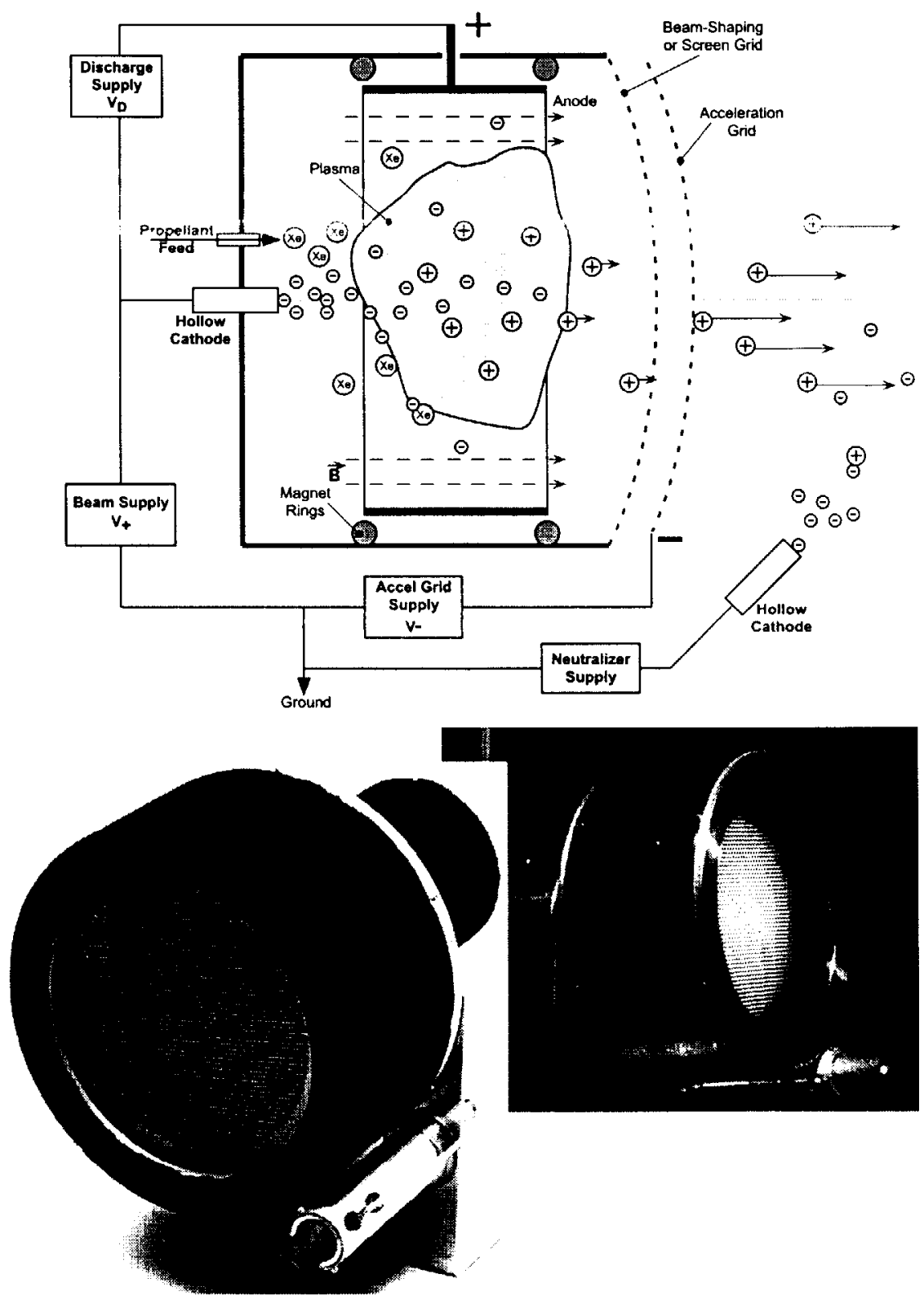


\section{VACUUM TEST FACILITY AT JPL}

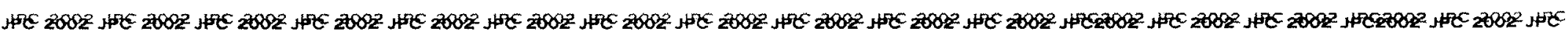

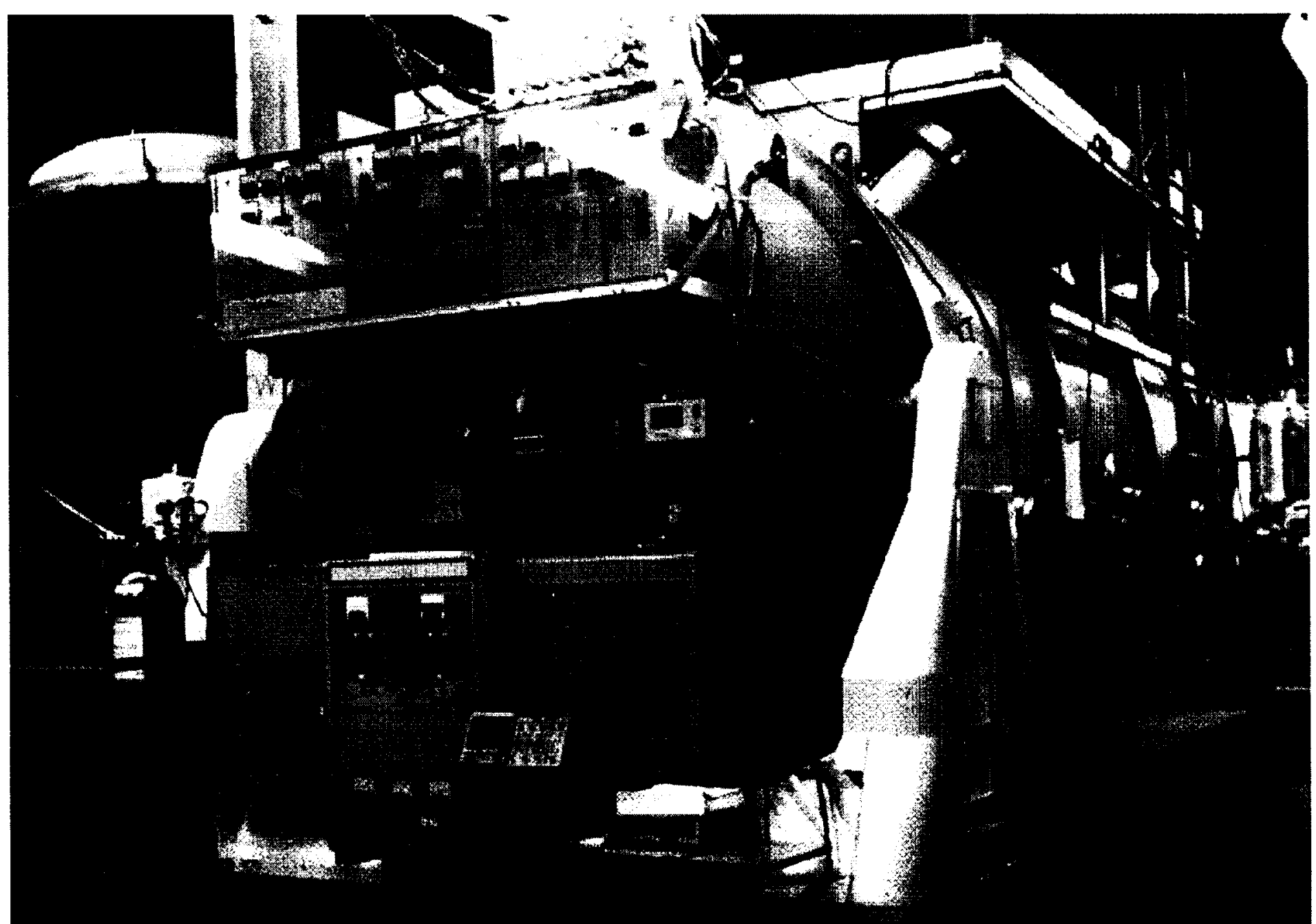




\section{EXPERIMENTAL SET-UP AT JPL}

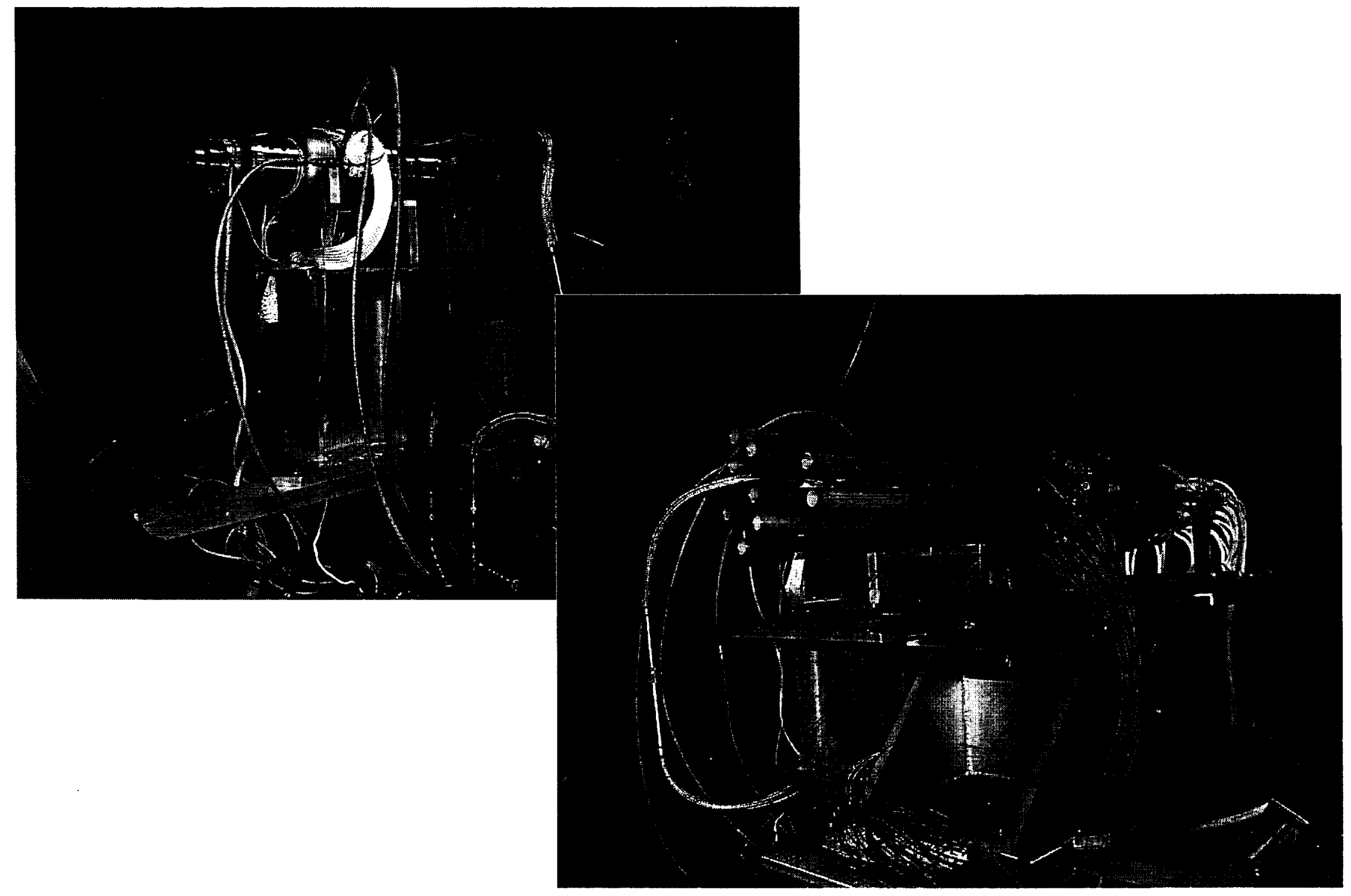




\section{EXPERIMENTAL SET-UP AT JPL}

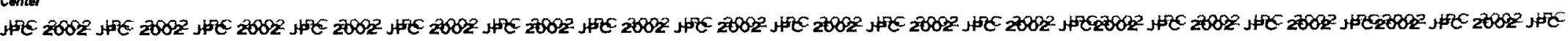

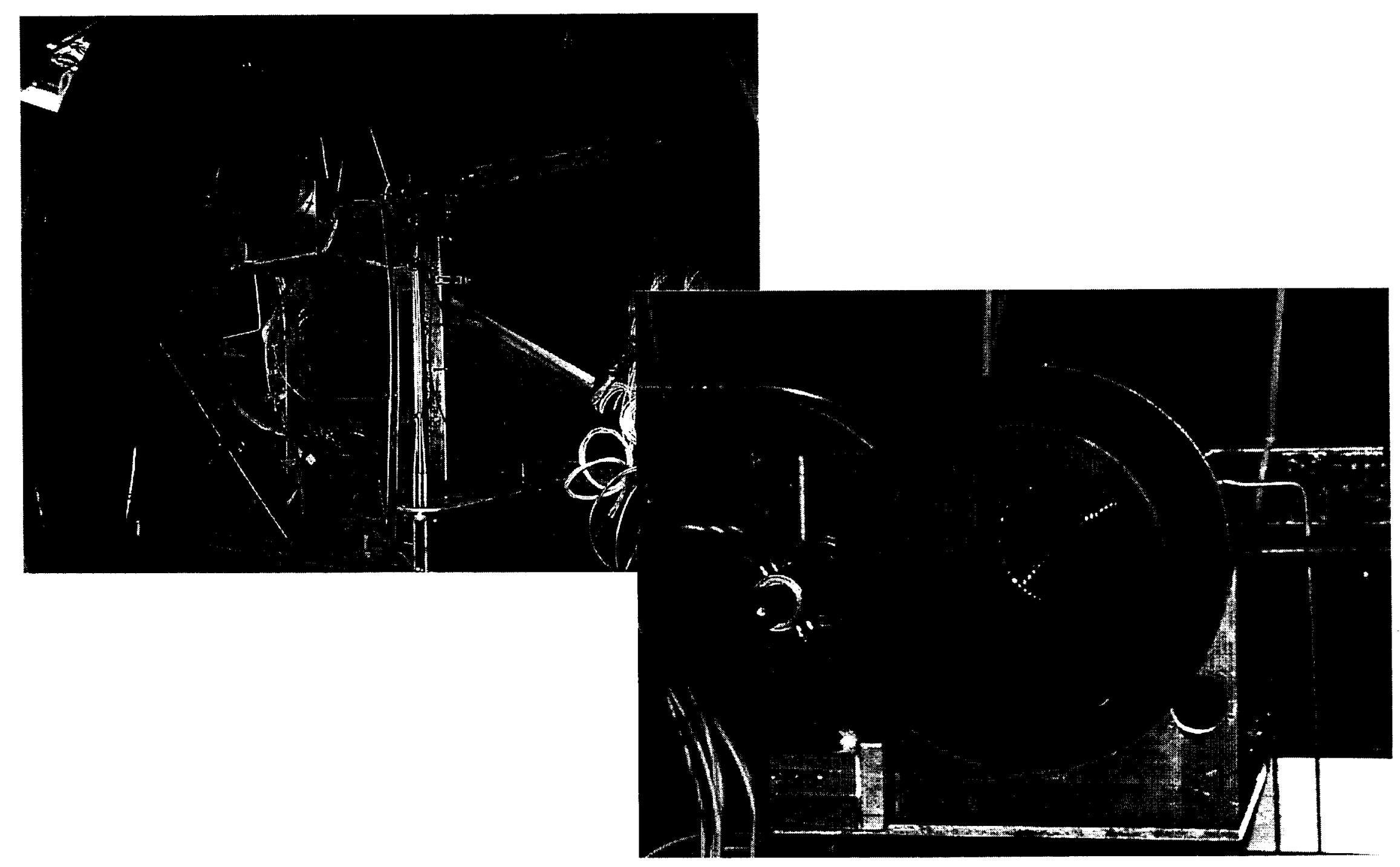




\section{RESULTS}

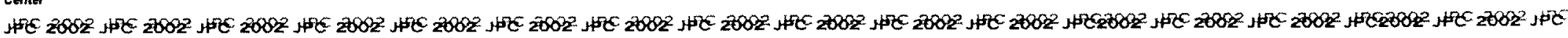

* Integration of powertrain components accomplished in phased approach.

* First successful operation of End-to-End System Demonstration beginning of December 2001.

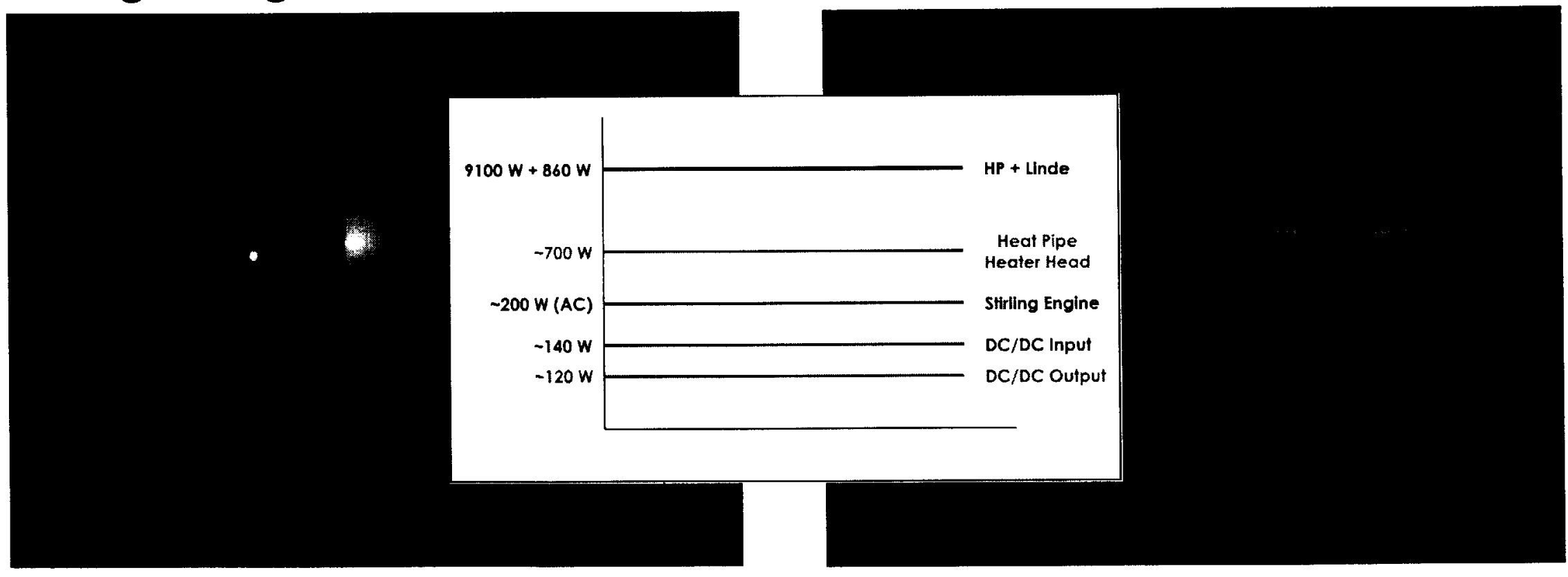

* Integrated system performs well and has no problems. * Stirling engine tuning underway. 


\section{SUMMARY}

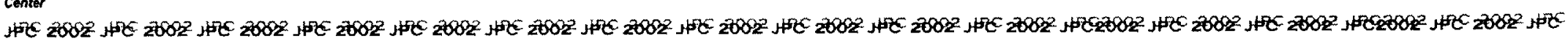

* Successful demonstration of a simulated (resistance-heated) nuclear system, conversion system and electric propulsion system.

* The end-to-end system demonstration sets a precedent for ground testing of nuclear electric propulsion systems.

* The end-to-end system identified and addressed a number of integration issues.

* This demonstration was accomplished with commercially available components and advanced cutting-edge technology.

* More extensive testing of the integrated system will be performed in the near future. 